\begin{tabular}{|c|l|}
\hline Title & Hydroformylation of 1-hexene using polymer-supported rhodium catalysts in supercritical carbon dioxide \\
\hline Author(s) & Fujita, Shin-Ichiro; A kihara, Shuji; Fuji isawa, Shinya; A rai, Masahiko \\
\hline Citation & $\begin{array}{l}\text { Journal of Molecular Catalysis A Chemical, 268(1-2), 244.250 } \\
\text { https://doi.org/10.1016/.molcata.2006.12.032 }\end{array}$ \\
\hline Issue Date & 2007-05-01 \\
\hline Doc URL & http://hdl.handle.net/2115/24256 \\
\hline Type & article (author version) \\
\hline File Information & JMCA 268-1-2.pdf \\
\hline
\end{tabular}

Instructions for use 


\title{
Hydroformylation of 1-hexene using polymer-supported rhodium catalysts in supercritical carbon dioxide
}

\author{
Shin-ichiro Fujita,* Shuji Akihara, Shinya Fujisawa, Masahiko Arai \\ Division of Chemical Process Engineering, Graduate School of Engineering, Hokkaido University, Sapporo \\ 060-8628, Japan.
}

\begin{abstract}
Hydroformylation of 1-hexene was carried out in supercritical $\mathrm{CO}_{2}\left(\mathrm{scCO}_{2}\right)$ and in organic solvents (toluene and ethyl acetate) using polymer-supported rhodium catalysts, which were prepared from polystyrene bound triphenylphosphine (TPP) and dicarbonylacetylecetonato rhodium. Preparation variables such as TPP/Rh ratio, time of rhodium precursor fixation on the support and time of syngas pretreatment do not indicate significant effects on the reaction. The product distribution slightly changes with $\mathrm{CO}_{2}$ pressure. It increases appreciably as $\mathrm{H}_{2}$ pressure is raised in $\mathrm{scCO}_{2}$ but $\mathrm{CO}$ retards the reaction. The influence of $\mathrm{H}_{2}$ pressure in scCO $\mathrm{SO}_{2}$ is slightly different from that in toluene. Changes of the structure of rhodium complexes on the polymer during the catalyst preparation and the reaction were investigated by diffuse reflectance FT-IR. It should be noted that the catalyst is recyclable for the reaction in $\mathrm{scCO}_{2}$ and the reaction rate and selectivity of the hydroformylation are much higher than those in the organic solvents.
\end{abstract}

Keywords: Hexene hydroformylation; Polystyrene; Heterogeneous catalyst; Catalyst recycling; Supercritical carbon dioxide.

\section{Introduction}

Supercritical carbon dioxide $\left(\mathrm{scCO}_{2}\right)$ is gaining considerable interest as an ecologically benign and economically feasible new generation reaction medium, which can replace conventional toxic, flammable organic solvents $[1,2]$. It allows various chemical substances to dissolve in it but it simply separates from them by depressurization (Fig.1a), and its several other advantages are non-flammability, non-toxicity and absence of a gas-liquid phase boundary. The physicochemical properties of $\mathrm{scCO}_{2}$ can be tuned within a certain range by adjusting the pressure and temperature, being additional parameters for optimization of reactions in it. 
Fig. 1

Homogeneous organometallic complexes are effective catalysts for various chemical transformations in conventional solvents [3]; however, they have a major drawback in their separation from product and recycling. One of the methods overcoming this drawback is using polymer-supported catalysts, in which metal complexes are immobilized on polymer surface through their surface functional groups [4-6]. Polymer-supported catalysts are easily separated and recyclable. Hence, the use of polymer-supported catalysts in $\mathrm{scCO}_{2}$ is very attractive, since, in this reaction system, both the catalyst and the solvent are easily separable (Fig. 1b). Recently, a few studies concerning such reaction systems have been reported for polymerization [7], hydrogenation [8-12] and hydroformylation [10,11]. Lopez-Castillo et al. [11] and Kayaki et al. [12] have shown that the catalysts are successfully recyclable for hydrogenation reactions. As reviewed by Cooper, $\mathrm{scCO}_{2}$ is a good plasticizer for polymers [13]. This strongly suggests that $\mathrm{scCO}_{2}$ would be a good swelling solvent for the polymer-supported catalysts, allowing substrates to come in contact with the metal complexes existing inside the bulk of the polymer. Since the ability of $\mathrm{scCO}_{2}$ to swell polymers changes by its pressure [14-16], the overall reaction rate may strongly depend on the $\mathrm{CO}_{2}$ pressure. The present work has been undertaken to study the features of $\mathrm{scCO}_{2}$ in hydroformylation of 1-hexene using polymer-supported rhodium complex catalysts. The effects of catalyst preparation and reaction conditions such as $\mathrm{CO}_{2}$, syngas $\left(\mathrm{CO} / \mathrm{H}_{2}\right)$, $\mathrm{CO}$ and $\mathrm{H}_{2}$ pressures on the reaction and the catalyst structure have been examined in detail.

\section{Experimental}

Polymer-supported rhodium catalysts were prepared from dicarbonylacetylacetonato rhodium (Wako) as a catalyst precursor and triphenylphosphine (TPP)-bound polystyrene cross linked with 2\% divinylbenzene (Aldrich) as a support. The quantity of TPP bound to the polymer given by the supplier is 3 mmol TPP per $1 \mathrm{~g}$ resin, which indicates the presence of one TPP species every 3-4 monomer units of polymer chain on average. In typical procedures, one gram of the polystyrene was added to $10 \mathrm{~cm}^{3}$ of toluene dissolving $0.5 \mathrm{mmol}$ of the precursor $(\mathrm{TPP} / \mathrm{Rh}=6)$ and the resultant suspension was kept at room temperature for $17 \mathrm{~h}$ under stirring to fix rhodium on the support (metal fixation). Then, the suspension was treated in a reactor with 1 MPa of syngas 
$\left(\mathrm{CO} / \mathrm{H}_{2}=1 / 1\right)$ at $70^{\circ} \mathrm{C}$ for $4 \mathrm{~h}$ under stirring. After this syngas treatment, the solids was filtered, washed with toluene several times and dried under vacuum. The catalyst thus prepared was kept in argon atmosphere. Measurements of the filtrate with an UV-VIS spectrophotometer showed that more than $99 \%$ of the initial amount of the rhodium precursor used was supported on the polymer. Assuming that complexes analogous to $\mathrm{HRh}(\mathrm{CO})(\mathrm{TPP})_{3}$ were formed on the polymer support, the loading of the complex was $0.46 \mathrm{mmol} / \mathrm{g}$-cat. Several catalysts were prepared under conditions in which TPP/Rh ratio and periods for the metal fixation and for the syngas treatment were changed. Also for those catalysts, more than $99 \%$ of the initial amounts of the rhodium precursor used were indicated to be supported on the polymer by UV/VIS spectroscopy measurements.

Hydroformylation experiments were carried out with a $50 \mathrm{~cm}^{3}$ high-pressure stainless steal reactor with a magnetic stirrer, a high-pressure liquid pump, and a backpressure regulator. In typical runs, the reactor was charged with $15.9 \mathrm{mmol}$ of 1-hexene and $0.3 \mathrm{~g}$ of the catalyst. After batch wise purging with $\mathrm{CO}_{2}$ at atmospheric pressure, the reactor was heated to a reaction temperature of $70^{\circ} \mathrm{C}$. Then, syngas $\left(\mathrm{CO} / \mathrm{H}_{2}=1 / 1\right)$ was charged to $4 \mathrm{MPa}$ followed by introduction of liquid $\mathrm{CO}_{2}$ to the desired pressure. The reaction was continued for $2 \mathrm{~h}$. After the reaction, the reactor was cooled by ice water to near room temperature and depressurized with the backpressure regulator. The reaction mixture was diluted with toluene to a certain volume after the separation of the polymer catalyst by filtration. Then, this solution was analyzed by a gas chromatograph packed with a capillary column using a flame ionization detector and a mass spectrometer. The concentrations of the substrate and products in the solution were determined from results obtained with authentic samples. For comparison, the reactions were also conducted in toluene and ethyl acetate instead of $\mathrm{CO}_{2}$. For the reaction runs using the catalysts having different TPP/Rh ratios, the total amount of rhodium was kept constant by changing the catalyst weight used.

Phase behavior of the reaction mixture was observed by naked eyes using a $10 \mathrm{~cm}^{3}$ reactor attached with sapphire windows. Diffuse reflectance FT-IR spectra of the polymer-supported rhodium catalysts were measured with an FT-IR spectroscopy (FT/IR-620, JASCO) with a spectral resolution of $2 \mathrm{~cm}^{-1}$. For the measurements, a spectrum of the polymer unloaded with rhodium was used as the background.

\section{Results and discussion}


Under the present reaction conditions, 1-heptanal 1, 2-methyl-1-hexanal 2 and 2-hexene 3 were formed via hydroformylation or isomerization (Scheme 1) and the product distribution was observed to change depending on the conditions of the catalyst preparation and the reaction, as will be described in the following.

\section{Scheme 1}

\section{Influence of the catalyst preparation conditions}

Table 1 shows the effects of the catalyst preparation conditions on the reaction. Neither the TPP/Rh ratio nor the time of the metal fixation has significant influence on the activity and the selectivity of the catalyst (entries 1-5). The catalyst prepared without the syngas pretreatment shows a lower selectivity for the isomerization (entry 6). Thus, these parameters of the catalyst preparation affect the reaction results but the influence is not so significant. On the basis of the results obtained, the catalyst prepared under the conditions where TPP/Rh ratio, the metal fixation time and the syngas pretreatment time were $6,17 \mathrm{~h}$ and $4 \mathrm{~h}$, respectively, was used for further experiments.

\section{Table 1}

\section{Influence of $\mathrm{CO}_{2}$ and syngas pressures}

Fig. 2 shows the influence of $\mathrm{CO}_{2}$ pressure on the hydroformylation of 1-hexene. The conversion does not change so much in the range of $\mathrm{CO}_{2}$ pressures examined. Naked eye observations showed that 1-hexene was completely dissolved in $\mathrm{scCO}_{2}$ under the conditions for Fig. 2 [17]. The product distribution slightly changes with $\mathrm{CO}_{2}$ pressure. The selectivity to 3 tends to increase with increasing $\mathrm{CO}_{2}$ pressure in compensation for the decrease of the selectivity to $\mathbf{1}$. The present authors previously reported the influence of $\mathrm{CO}_{2}$ pressure on the hydroformylation reactions of 1-hexene and 1,5-hexadiene with homogeneous rhodium fluorinated phosphine complexes in $\mathrm{scCO}_{2}[17,18]$ and showed that minima of aldehyde yields appeared at a $\mathrm{CO}_{2}$ pressure of $9 \mathrm{MPa}$. In the cases of the 1-hexene hydroformylation, the yield of 1 observed at $8 \mathrm{MPa}$ was around $50 \%$ and this was reduced to $35 \%$ or below at $9 \mathrm{MPa}$ depending on the structure of the fluorinated phosphine ligand used. It was proposed that the solvent nature of $\mathrm{scCO}_{2}$ at $9 \mathrm{MPa}$ should be different from that at lower and higher pressures, resulting in the lower yields. This was inferred from a fact that the formation of colloidal metal particles was observed at this pressure only but not at lower and higher pressures [17]. The $\mathrm{CO}_{2}$ 
solvent could affect the properties of homogeneous phosphine-Rh catalysts at about 9 MPa under the reaction conditions examined. Compared with the previous results of the homogeneous reactions, the difference in the conversion between the pressures of 8 and $9 \mathrm{MPa}$ of Fig. 2 is small. The influence of $\mathrm{CO}_{2}$ should be insignificant for the heterogeneous catalysts in which the active Rh species are fixed onto the polymer chains (these are occluded in the three-dimensional polymer network), as compared with the unsupported free Rh species in the homogeneous reactions. The three-dimensional polymer network may stabilize the fixed $\mathrm{Rh}$ complex. More detailed discussion at molecular level is not possible at present, for which information about the working structure of polymer network and fixed TPP-Rh complexes at different $\mathrm{CO}_{2}$ pressures is further necessary.

Fig. 2

In other reactions in $\mathrm{scCO}_{2}$, a drastic decrease in the product yield with increasing $\mathrm{CO}_{2}$ pressure was sometimes observed [19-25]. This has been ascribed to dilution effect of $\mathrm{scCO}_{2}$. However, this dilution effect is not significant for the present reaction system, as indicated from Fig. 2. Since the ability of $\mathrm{scCO}_{2}$ to swell polymers is enhanced by increasing the $\mathrm{CO}_{2}$ pressure [14-16] and this would make the movement of the substrates toward the catalytic species inside the polymer easier, one can expect that the overall reaction rate increases with the pressure and this enhancement may cancel the dilution effect. However, this explanation is not plausible, because similar effects of $\mathrm{CO}_{2}$ pressure were observed even for the hydroformylation in $\mathrm{scCO}_{2}$ using homogeneous complex catalysts $[17,18]$. It has been postulated that $\mathrm{scCO}_{2}$ may improve the overall reaction rate of hydroformylation at higher pressures, resulting in canceling the dilution effect, although the details are not known [18]. Probably, the swelling ability of $\mathrm{scCO}_{2}$ at low pressures should be enough to allow the substrates to diffuse rapidly into the polymer support network. The details are still unknown about which reaction steps of catalytic hydroformylation cycle are influenced and accelerated by dense $\mathrm{CO}_{2}$ molecules. But Palo and Erkey [26] showed that the reaction order on $\mathrm{H}_{2}$ pressure for 1-octene hydroformylation in $\mathrm{scCO}_{2}$ was smaller (about 0.5 ) than those in organic solvents, where the reaction rates were usually first-order in $\mathrm{H}_{2}$ pressure. They proposed that the rate-determining step in the catalytic cycle changes in $\mathrm{scCO}_{2}$ due to higher $\mathrm{H}_{2}$ concentration in $\mathrm{scCO}_{2}$ and/or $\mathrm{scCO}_{2}$ solvent effect. Additionally, an important point may be pointed out here that dense $\mathrm{CO}_{2}$ molecules can selectively modify the reactivity of a certain group of a multifunctional substrate; for an $\alpha, \beta$-unsaturated aldehyde of cinnamaldehyde having $\mathrm{C}=\mathrm{C}$ and $\mathrm{C}=\mathrm{O}$ bonds, the latter becomes 
more reactive in the presence of pressurized $\mathrm{CO}_{2}$ than the former, as indicated by in situ high-pressure FTIR measurements $[27,28]$. This can explain the improvement in the selective hydrogenation of the carbonyl group as observed. It is thus suggested that some steps of hydroformylation involving certain chemical species are also influenced by dense $\mathrm{CO}_{2}$ molecules at elevated pressures.

Influence of syngas $\left(\mathrm{CO} / \mathrm{H}_{2}\right), \mathrm{H}_{2}$ and $\mathrm{CO}$ pressures on the title reaction was also investigated at a $\mathrm{CO}_{2}$ pressure of $12 \mathrm{MPa}$. The results obtained are summarized in Table 2. The syngas pressure does not have significant influence on the yields of $\mathbf{1}$ and $\mathbf{2}$, but a slight decrease of $\mathbf{3}$ is observed at 6 MPa (entries 1-3). When $\mathrm{H}_{2}$ pressure is changed from $2 \mathrm{MPa}$ to $4 \mathrm{MPa}$, the aldehyde yields are enhanced (entries 2, 4). However, the extent of enhancement levels off above 4 MPa (entries 2, 4-6). This suggests that the hydroformylation rate tends to be saturated at the high $\mathrm{H}_{2}$ pressure region. The yield of $\mathbf{3}$ gradually decreases with the $\mathrm{H}_{2}$ pressure. On the other hand, higher CO pressure retards the reaction (entries 2,7,8).

\section{Table 2}

Under the conditions for entry 2 in Table 2, the turnover frequency for the total formation of $\mathbf{1}$ and $\mathbf{2}$ was $35 \mathrm{~h}^{-1}$, and the $\mathbf{1} / \mathbf{2}$ ratio was 2.7. Among homogeneous rhodium-fluorinated phosphine complexes tested for the same reaction in $\mathrm{scCO}_{2}$ [17], a rhodium tris(p-fluoromethyl phenyl)phosphine complex was the most active for the hydroformylation. This homogeneous complex gave a turnover frequency of $41 \mathrm{~h}^{-1}$ for the total aldehyde formation and a $\mathbf{1} / \mathbf{2}$ ratio of 2.3 at the same reaction conditions as those for entry 2 . Thus, the activity of the polymer-supported catalyst is comparable and its selectivity for the linear aldehyde is slightly higher compared with the homogeneous catalyst previously used. The comparable turnover frequency suggests that all Rh species supported on the polymer are effectively used for the reaction.

\section{Catalyst recycling}

The polymer-supported rhodium catalyst was repeatedly used for the reaction. After a reaction run, the catalyst was separated by decantation, washed with toluene several times and dried in argon atmosphere. Then, the catalyst was used for the next reaction run. As shown in Fig. 3, the catalyst with a Rh/TPP ratio of 6 is recyclable without deactivation at least three times, although the yield of $\mathbf{3}$ tends to increase somewhat. However, the structure of rhodium complexes was suggested to change in the course of the reaction runs. This was discussed in the next section. Similar results were obtained with the catalyst having a TPP/Rh ratio of 2. 
This catalyst was also recyclable without deactivation.

Fig. 3

\section{Diffuse reflectance FT-IR spectroscopy}

Fig. 4 illustrates diffuse reflectance FT-IR spectra measured before and after the syngas pretreatment and after the hydroformylation for the catalyst having a TPP/Rh ratio of 6 . In the spectrum before the syngas pretreatment, the characteristic peaks of the rhodium precursor, $\mathrm{Rh}(\mathrm{CO})_{2}(\mathrm{acac})$, are not seen at 2058 and 1970 $\mathrm{cm}^{-1}$ and only one peak is observed at $1980 \mathrm{~cm}^{-1}$, which is typical for rhodium monocarbonyl species, $\mathrm{Rh}(\mathrm{CO})(\mathrm{acac})(\mathrm{TPP})$, [29-31]. After the syngas pretreatment (spectrum b), the intensity of the peak at 1980 $\mathrm{cm}^{-1}$ decreases, two peaks appear at 2000 and $1930 \mathrm{~cm}^{-1}$ and no peak around $2040 \mathrm{~cm}^{-1}$ ascribable to Rh-H stretching band is discernible. The two peaks can be assigned to dicarbonyl species, $\mathrm{Rh}(\mathrm{CO})_{2}(\mathrm{TPP})_{2}$, according to the study on polymer supported rhodium catalysts by Zeelie et al. [31] who show by NMR that rhodium monophosphine complexes supported on the polymer converts to rhodium diphosphine complexes in $\mathrm{CO} / \mathrm{H}_{2}$. After the reaction (spectrum c), new bands appear at 2040 and $2070 \mathrm{~cm}^{-1}$. The former band strongly suggests the presence of $\mathrm{Rh}$ hydride species. On the other hand, the latter one suggests that a part of the rhodium dicarbonyl species is transformed during the reaction to tricarbonyl species with the ligation of acyl group, $\mathrm{Rh}(\mathrm{CO})_{3}\left(\mathrm{COC}_{6} \mathrm{H}_{13}\right)(\mathrm{TPP})$ [32], or without it, $\mathrm{Rh}(\mathrm{CO})_{3}(\mathrm{TPP})$ [31]. Similar FT-IR spectra were obtained with the catalyst of a TPP/Rh ratio of 4 . Fig. 5 depicts the FT-IR spectra obtained with the catalyst whose TPP/Rh ratio was 2. Similar to the other catalysts, the band of $\mathrm{Rh}(\mathrm{CO})(\mathrm{acac})(\mathrm{TPP})$ appears at $1980 \mathrm{~cm}^{-1}$ in the spectrum obtained before the syngas pretreatment. However, after the pretreatment, a strong band ascribable to tricarbonyl species is seen at $2080 \mathrm{~cm}^{-1}$ along with the bands of dicarbonyl species. Since the band of hydride species at $2040 \mathrm{~cm}^{-1}$ is absent, the tricarbonyl species would be $\mathrm{Rh}(\mathrm{CO})_{3}(\mathrm{TPP})$. When the TPP/Rh ratio is low, the relative quantity of TPP available for the ligation to rhodium atoms would be small. This would result in the formation of a larger fraction of tricarbonyl species, which need smaller amounts of TPP moieties. After a reaction run, the strong band of tricarbonyl species remains in the IR spectra. Probably, a part of this band should be ascribed to $\mathrm{Rh}(\mathrm{CO})_{3}\left(\mathrm{COC}_{6} \mathrm{H}_{13}\right)(\mathrm{TPP})$.

Fig. 4

Fig. 5 
Thus, the changes of rhodium complexes during the catalyst preparation and the reaction can be illustrated as Scheme 2. Dicarbonyl species, $\mathrm{Rh}(\mathrm{CO})_{2}(\mathrm{TPP})_{2}$, would be transformed to $\mathrm{HRh}(\mathrm{CO})_{2}(\mathrm{TPP})_{2}$, which is further converted to a intermediate $\mathrm{HRh}(\mathrm{CO})(\mathrm{TPP})_{2}$ that initiates the catalytic cycle of hydroformylation [ 26,31, 33-35]. Tricarbonyl species of $\mathrm{Rh}(\mathrm{CO})_{3}(\mathrm{TPP})$ and $\mathrm{Rh}(\mathrm{CO})_{3}\left(\mathrm{COC}_{6} \mathrm{H}_{13}\right)(\mathrm{TPP})$ could be produced from $\mathrm{Rh}(\mathrm{CO})_{2}(\mathrm{TPP})_{2}$ and $\mathrm{Rh}(\mathrm{CO})\left(\mathrm{COC}_{6} \mathrm{H}_{13}\right)(\mathrm{TPP})_{2}$, respectively. This monocarbonyl species is also involved in the catalytic cycle. When the TPP/Rh ratio is 2, although the fraction of tricarbonyl species in the total rhodium atoms is larger compared with the other larger ratios, the reaction results obtained are not different so much (Table 1). One possible explanation for this is that the conversions between $\mathrm{Rh}(\mathrm{CO})_{2}(\mathrm{TPP})_{2}$ and $\mathrm{Rh}(\mathrm{CO})_{3}(\mathrm{TPP})$ and between $\mathrm{Rh}(\mathrm{CO})\left(\mathrm{COC}_{6} \mathrm{H}_{13}\right)(\mathrm{TPP})_{2}$ and $\mathrm{Rh}(\mathrm{CO})_{3}\left(\mathrm{COC}_{6} \mathrm{H}_{13}\right)(\mathrm{TPP})$ would be irreversible and rapid under the hydroformylation conditions. Under such conditions, the amounts of $\mathrm{HRh}(\mathrm{CO})(\mathrm{TPP})_{2}$ and $\mathrm{Rh}(\mathrm{CO})\left(\mathrm{COC}_{6} \mathrm{H}_{13}\right)(\mathrm{TPP})_{2}$ intermediates could be nearly the same irrespective of the $\mathrm{TPP} / \mathrm{Rh}$ ratio and hence the ratio is insignificant for the reaction. This can explain that the fractional structure change of the rhodium complexes before and after the reaction does not cause deactivation (Fig. 3). Another possible explanation is the presence of two types of 16-elctron intermediates, $\mathrm{HRh}(\mathrm{CO})(\mathrm{TPP})_{2}$ and $\mathrm{HRh}(\mathrm{CO})_{2}$ (TPP) (for the latter $\mathrm{L}=\mathrm{CO}$ in Scheme 2), as several authors proposed [26,31,35]. Kiss et al. [35] carried out the ethane hydroformylation with homogeneous Rh-TPP complex catalysts and showed that the reaction kinetics was changed by the ligand concentration, i.e. the TPP/Rh ratio. They proposed that the catalytic cycle can be initiated by both $\mathrm{HRh}(\mathrm{CO})(\mathrm{TPP})_{2}$ and $\mathrm{HRh}(\mathrm{CO})_{2}(\mathrm{TPP})$ whose amounts depend on the ligand concentration. The intermediate $\mathrm{HRh}(\mathrm{CO})_{2}(\mathrm{TPP})$ can be produced from $\mathrm{Rh}(\mathrm{CO})(\mathrm{acac})(\mathrm{TPP})$ through the formations of $\mathrm{Rh}(\mathrm{CO})_{3}(\mathrm{TPP})$ and $\mathrm{HRh}(\mathrm{CO})_{3}(\mathrm{TPP})(\mathrm{L}=\mathrm{CO}$ in Scheme 2). If the reaction rate does not change so much by the type of the intermediate initiating the catalytic cycle, the fraction of tricarbonyl species has little effects on the reaction. Thus, the TPP/Rh ratio would not cause significant effects on the yields.

\section{Scheme 2}

The FT-IR results indicate that probable Rh complexes are the forms including one or two TPP species at a P/Rh ratio of 6 or 4 . It is thus assumed that a certain fraction, $50 \%$ or less, of all the bound TPP species are used for the formation of the Rh complexes but the rest is unused. Since the polymer is cross-linked and the density of TPP is large, two TPP species of the same and/or different polymer chains may coordinate to the same Rh complex. 


\section{Hydroformylation in organic solvents}

For comparison, the title reaction was also carried out in toluene and ethyl acetate. The reaction results obtained are listed in Table 3 along with that obtained in $\mathrm{scCO}_{2}$. For these runs, the concentrations of the catalyst and the olefin were the same as those for the experiment in $\mathrm{scCO}_{2}$ in which all olefin used was dissolved. It is seen that the organic solvents give the lower yields of $\mathbf{1}$ and $\mathbf{2}$ but the higher yields of $\mathbf{3}$ than those with $\mathrm{scCO}_{2}$. Toluene and ethyl acetate are also good solvents for polystyrene, similar to dense $\mathrm{CO}_{2}$, and the polymer support may swell well in these organic solvents, resulting in the formation of similar $\mathrm{Rh}$ complexes as suggested by FT-IR measurements (Fig. 6). The differences in the total conversion and the product selectivity observed between those solvents are unlikely to be explained by the catalyst structure. As discussed previously $[17,18]$, the concentrations of $\mathrm{H}_{2}$ and $\mathrm{CO}$ in the organic solvents are lower than those in $\mathrm{scCO}_{2}$, resulting in the lower reaction rate and selectivity of hydroformylation. Thus, $\mathrm{scCO}_{2}$ is superior to the organic solvents for the title reaction.

Table 3

Fig. 6

Fig. 7 compares the dependence of the formation of $\mathbf{1}$ on the $\mathrm{H}_{2}$ pressure between $\mathrm{scCO}_{2}$ and toluene. In both the solvents, the yield gradually increases with increasing $\mathrm{H}_{2}$ pressure; however, the yield in $\mathrm{scCO}_{2}$ tends to be saturated at higher $\mathrm{H}_{2}$ pressure. As already mentioned, Palo and Erkey [26] showed that the reaction order on $\mathrm{H}_{2}$ pressure for 1-octene hydroformylation in $\mathrm{scCO}_{2}$ was smaller than those in organic solvents. Probably, such effects of $\mathrm{scCO}_{2}$ should cause the different dependence of the aldehyde yield on the $\mathrm{H}_{2}$ pressure from that in toluene, although the difference in the dependence of the aldehyde yield between $\mathrm{scCO}_{2}$ and toluene in the present reaction system is less marked than that observed in the homogeneous system reported by Palo and Erkey.

Fig. 7

The influence of syngas and CO pressures was also examined in toluene (Table 4). When the syngas pressure was raised from $2 \mathrm{MPa}$ to $4 \mathrm{MPa}$, the total yield of the aldehydes increased (entries 1, 2). However, further increase of the pressure did not enhance the total yield so much (entry 3). The influence of the syngas 
pressure on the reaction in toluene is slightly different from that in $\mathrm{scCO}_{2}$. On the other hand, similar to the reaction in $\mathrm{scCO}_{2}$, $\mathrm{CO}$ retarded the reaction (entries 2, 4, 5).

\section{Table 4}

In conclusion, the hydroformylation of 1-hexene in $\mathrm{scCO}_{2}$ using the polymer supported rhodium catalyst was investigated in the present study. A few catalyst preparation variables examined and the pressures of $\mathrm{CO}_{2}$ and syngas do not have significant effects on the reaction. Increasing the $\mathrm{H}_{2}$ pressure enhances the aldehyde formation, while increasing the $\mathrm{CO}$ pressure reduces it. The catalyst is easily recyclable. It is important to note that $\mathrm{scCO}_{2}$ gives better yields of the aldehydes than conventional organic solvents of toluene and ethyl acetate. The present reaction system would give an effective process for the aldehyde synthesis, since both $\mathrm{scCO}_{2}$ and the polymer supported catalyst are easily separable and recyclable.

\section{References}

[1] P. G. Jessop, T. Ikariya, R. Noyori, Chem. Rev. 99 (1999) 475.

[2] R. S. Oakes, A. A. Clifford, C. M. Rayner, J. Chem. Soc. Perkin Trans. 1 (2001) 917.

[3] For an example, B. Cornils, W. A. Herrmann, Applied Homogeneous Catalysis with Organometallic Compounds, VCH, New York, 2000.

[4] S. V. Ley, I. R. Baxendale, R. N. Bream, P. S. Jackson, A. G. Leach, D. A. Longbottom, M. Nesi, J. S. Scott, R. I. Storer, S. J. Taylor, J. Chem. Soc. Perkin. Trans. 1 (2000) 3815.

[5] N. E. Leadbeater, M. Marco, Chem. Rev. 102 (2002) 3217.

[6] C. A. McNamara, M. J. Dixon, M. Bradley, Chem. Rev. 102 (2000) 3257.

[7] L. M. Stamp, S. A. Mang, A. B. Holmes, K. A. Knights, Y. R. de Miguel, I. F. McConvey, Chem. Commun. (2001) 2502.

[8] H. G. Niessen, A. Eichhorn, K. Woelk, J. Bargon, J. Mol. Catal. A: Chem. 182-183 (2002) 463.

[9] I. Kani, M. A. Omary, M. A. Rawashdeh-Omary, Z. K. Lopez-Catillo, R. Flores, A. Akgerman, J. P. 
Fackler Jr., Tetrahedron 58 (2002) 3923.

[10] Z. K. Lopez-Catillo, R. Flores, I. Kani, J. P. Fackler Jr., A. Akgerman, Ind. Eng. Chem. Res. 41 (2002) 3075.

[11] Z. K. Lopez-Catillo, R. Flores, I. Kani, J. P. Fackler Jr., A. Akgerman, Ind. Eng. Chem. Res. 42 (2003) 3893.

[12] Y. Kayaki, Y. Shimokawatoko, T. Ikariya, Adv. Synth. Catal. 345 (2003) 175.

[13] A. I. Cooper, J. Mater. Chem. 10 (2000) 207 and references cited therein.

[14] J. J. Shim, K. P. Johnston, AIChE J. 37 (1991) 607.

[15] J. J. Watkins, T. J. McCarthy, Macromolecules 28 (1995) 4067.

[16] P. Rajagopalan, T. J. McCarthy, Macromolecules 31 (1998) 4791.

[17] S. Fujita, S. Fujisawa, B. M. Bhanage, Y. Ikushima, M. Arai, New J. Chem. 26 (2002) 1479.

[18] S. Fujita, S. Fujisawa, B. M. Bhanage, Y. Ikushima, M. Arai, Eur. J. Org. Chem. 2004 (2004) 2881.

[19] T. Sakakura, Y. Saito, M. Okano, J. C. Choi, T. Sako, J. Org. Chem. 63 (1998) 7095.

[20] H. Kawanami, Y. Ikushima, Chem. Commun. (2000) 2089.

[21] S. Fujita, B. M. Bhanage, Y. Ikushima, M. Arai, Green Chem. 3 (2001) 87.

[22] H. Kawanami, Y. Ikushima, J. Jpn. Petrol. Inst. 45 (2002) 321.

[23] H. Kawanami, Y. Ikushima, Tetrahedron Lett. 43 (2002) 3841.

[24] B. M. Bhanage, S. Fujita, Y. Ikushima, K. Torii, M. Arai, Green Chem. 5 (2003) 71.

[25] H. Kawanami, Y. Ikushima, Chem. Commun. (2003) 896.

[26] D. Palo, C. Erkey, Ind. Eng. Chem. Res. 38 (1999) 3786.

[27] F. Zhao, S. Fujita, J. Sun, Y. Ikushima, M. Arai, Chem. Commun. (2004) 2326.

[28] F. Zhao, S. Fujita, S. Akihara, M. Arai, J. Phys. Chem. A, 109 (2005) 4419.

[29] F. Bonati, G. Wilkinson, J. Chem. Soc. (1964) 3156.

[30] P. E. Garrou, G. E. Harwell, Inorg. Chem. 15 (1976) 646.

[31] T. A. Zeelie, A. Root, A. O. I. Krause, Appl. Catal. A: Gen. 285 (2005) 96.

[32] G. Yagupsky, C. K. Brown, G. Wilkinson, J. Chem. Soc. A (1970) 1392. 
[33] D. Evans, J. A. Osborn, G. Wilkinson, J. Chem. Soc. A (1968) 3133.

[34] W. R. Moser, C. J. Papile, D. A. Brannon, R. A. Duwell, S. J. Weininger, J. Mol. Catal. 41 (1987) 271.

[35] G. Kiss, E. J. Mozeleski, K. C. Nadler, E. VanDriessche, C. DeRoover, J. Mol. Catal. A: Chem. 138 (1999) 155. 


\section{Captions for tables, schemes and figures.}

Table 1 Influence of catalyst preparation conditions on hydroformylation of 1-hexene catalyzed by polymer-supported rhodium catalyst in $\mathrm{scCO}_{2}$.

Table 2 Influence of $\mathrm{H}_{2}$ and $\mathrm{CO}$ pressures on hydroformylation of 1-hexene catalyzed by polymer-supported rhodium catalyst in $\mathrm{scCO}_{2}$.

Table 3 Hydroformylation of 1-hexene catalyzed by polymer-supported rhodium catalyst in organic solvent.

Table 4 Influence of $\mathrm{H}_{2}$ and $\mathrm{CO}$ pressures on hydroformylation of 1-hexene catalyzed by polymer-supported rhodium catalyst in toluene.

Scheme 1. Hydroformylation of 1-hexene

Scheme 2. Changes of rhodium complex structure during the catalyst preparation and the reaction. TPP = polystyrene bound triphenylphosphine

Fig. 1. Reaction systems in $\mathrm{scCO}_{2}$ using a homogeneous catalyst (a) and a polymer-supported catalyst (b).

Fig. 2. Influence of $\mathrm{CO}_{2}$ pressure on hydroformylation of 1-hexene in $\mathrm{scCO}_{2}$ catalyzed by polymer-supported rhodium complex. ( $\square$ ), 1; ( $\square$ ), 2; ( $\square$ ), 3. Reaction conditions: substrate, 15.9 mmol; catalyst, 0.3 g (Rh = $138 \mu \mathrm{mol})$; TPP/Rh, 6; syngas, $4 \mathrm{MPa}$; temperature, $70^{\circ} \mathrm{C}$; time, $2 \mathrm{~h}$.

Fig. 3. Recycling of polymer-supported rhodium catalyst for hydroformylation of 1-hexene in scCO 2 ( $\square$ ), 1; $\square$ ), 2; ( $\square$ ), 3. Reaction conditions: substrate, 15.9 mmol; $\mathrm{CO}_{2}, 12 \mathrm{MPa}$; catalyst, $0.3 \mathrm{~g}(\mathrm{Rh}=138 \mu \mathrm{mol})$; TPP/Rh, 6; syngas, $4 \mathrm{MPa}$; temperature, $70^{\circ} \mathrm{C}$; time, $2 \mathrm{~h}$.

Fig. 4. Diffuse reflectance FT-IR spectra of polymer-supported rhodium catalyst measured (a) before and (b) after the syngas pretreatment and (c) after the hydroformylation in $\mathrm{scCO}_{2}$. TPP/Rh, 6; fixation time, $17 \mathrm{~h}$. The 
reaction conditions for the hydroformylation were the same with those for Fig. 3.

Fig. 5. Diffuse reflectance FT-IR spectra of polymer-supported rhodium catalyst with a TPP/Rh ratio of 2 measured (a) before and (b) after the syngas pretreatment and (c) after the hydroformylation in $\mathrm{scCO}_{2}$. Fixation time, $17 \mathrm{~h}$. The reaction conditions for the hydroformylation were the same with those for Fig. 3.

Fig. 6. A diffuse reflectance FT-IR spectrum of polymer-supported rhodium catalyst measured after the hydroformylation in toluene. TPP/Rh, 6; fixation time, $17 \mathrm{~h}$. The reaction conditions for the hydroformylation were the same with those for Table 3.

Fig. 7. Influence of $\mathrm{H}_{2}$ pressure on the yield of heptanal $\mathbf{1}(\mathrm{O})$ in $\mathrm{scCO}_{2}$ and $(\bigcirc)$ in toluene. Reaction conditions: substrate, $15.9 \mathrm{mmol}$; catalyst, $0.1 \mathrm{~g}(\mathrm{Rh}=46 \mu \mathrm{mol})$; TPP/Rh, 6; CO, $2 \mathrm{MPa}$; temperature, $70^{\circ} \mathrm{C}$; time, 2 h. Note that the catalyst amount is different from those for Fig. 1 and Table 3. 
Table 1 Influence of catalyst preparation conditions on hydroformylation of 1-hexene catalyzed by polymer-supported rhodium catalyst in $\mathrm{scCO}_{2}$.

\begin{tabular}{lcccc}
\hline Entry & TPP/Rh & \multicolumn{3}{c}{ Yield (\%) } \\
\cline { 3 - 5 } & $(-)$ & $\mathbf{1}$ & $\mathbf{2}$ & $\mathbf{3}$ \\
\hline 1 & 2 & 66.0 & 25.2 & 3.9 \\
2 & 4 & 63.7 & 23.7 & 3.9 \\
3 & 6 & 65.7 & 24.0 & 3.4 \\
$4^{\mathrm{a}}$ & 6 & 65.0 & 23.7 & 3.0 \\
$5^{\mathrm{b}}$ & 6 & 67.0 & 22.7 & 3.9 \\
$6^{\mathrm{c}}$ & 6 & 62.8 & 23.8 & 1.9 \\
\hline
\end{tabular}

Reaction conditions: 1-hexene, $15.9 \mathrm{mmol}$; Rh, $138 \mu \mathrm{mol}$; CO/ $\mathrm{H}_{2}, 4 \mathrm{MPa} ; \mathrm{CO}_{2}, 8 \mathrm{MPa}$; temperature, $70^{\circ} \mathrm{C}$; time, $2 \mathrm{~h}$.

${ }^{\mathrm{a}, \mathrm{b}}$ The periods for the precursor fixation were 1 and $4 \mathrm{~h}$, respectively.

${ }^{\mathrm{c}}$ Without the syngas pretreatment. 
Table 2 Influence of $\mathrm{H}_{2}$ and $\mathrm{CO}$ pressures on hydroformylation of 1-hexene catalyzed by polymer-supported rhodium catalyst in $\mathrm{scCO}_{2}$.

\begin{tabular}{lccccc}
\hline Entry & \multicolumn{3}{c}{ Pressure (MPa) } & \multicolumn{3}{c}{ Yield (\%) } \\
\cline { 2 - 6 } & $\mathrm{H}_{2}$ & $\mathrm{CO}$ & $\mathbf{1}$ & $\mathbf{2}$ & $\mathbf{3}$ \\
\hline 1 & 1 & 1 & 41.8 & 14.1 & 3.3 \\
2 & 2 & 2 & 44.2 & 16.5 & 5.9 \\
3 & 3 & 3 & 45.6 & 17.4 & 0.1 \\
4 & 4 & 2 & 57.3 & 21.2 & 4.6 \\
5 & 6 & 2 & 61.1 & 23.4 & 3.7 \\
6 & 8 & 2 & 67.5 & 25.9 & 1.5 \\
7 & 2 & 4 & 18.2 & 6.8 & trace \\
8 & 2 & 6 & 10.6 & 4.0 & trace \\
\hline
\end{tabular}

Reaction conditions: substrate, 15.9 mmol; catalyst, $0.3 \mathrm{~g}(\mathrm{Rh}=138 \mu \mathrm{mol})$; TPP/Rh, 6; $\mathrm{CO}_{2}, 12$ $\mathrm{MPa}$; temperature, $60^{\circ} \mathrm{C}$; time, $2 \mathrm{~h}$. 
Table 3 Hydroformylation of 1-hexene catalyzed by polymer-supported rhodium catalyst in organic solvent.

\begin{tabular}{lccc}
\hline \multicolumn{1}{c}{ Solvent } & \multicolumn{3}{c}{ Yield (\%) } \\
\cline { 2 - 4 } & $\mathbf{1}$ & $\mathbf{2}$ & $\mathbf{3}$ \\
\hline $\mathrm{CO}_{2}(12 \mathrm{MPa})$ & 61.5 & 23.1 & 6.5 \\
Toluene & 38.6 & 16.4 & 20.0 \\
Ethyl acetate & 47.1 & 19.2 & 22.3
\end{tabular}

Reaction conditions: toluene and ethyl acetate, $9.6 \mathrm{~cm}^{3} ; 1$-hexene, $3.2 \mathrm{mmol} / \mathrm{dm}{ }^{3} ; \mathrm{Rh}, 27.6$ $\mathrm{mmol} / \mathrm{dm}^{3}$; TPP/Rh, 6; CO/H $2,4 \mathrm{MPa}$; temperature, $70^{\circ} \mathrm{C}$; time, $2 \mathrm{~h}$. 
Table 4 Influence of $\mathrm{H}_{2}$ and $\mathrm{CO}$ pressures on hydroformylation of 1-hexene catalyzed by polymer-supported rhodium catalyst in toluene.

\begin{tabular}{lccccc}
\hline Entry & \multicolumn{2}{c}{ Pressure (MPa) } & \multicolumn{3}{c}{ Yield (\%) } \\
\cline { 2 - 6 } & $\mathrm{H}_{2}$ & CO & $\mathbf{1}$ & $\mathbf{2}$ & $\mathbf{3}$ \\
\hline 1 & 1 & 1 & 12.9 & 5.0 & 2.2 \\
2 & 2 & 2 & 20.8 & 8.2 & trace \\
3 & 3 & 3 & 22.3 & 9.3 & trace \\
4 & 2 & 4 & 10.6 & 4.2 & trace \\
5 & 2 & 6 & 4.4 & 1.9 & trace
\end{tabular}

Reaction conditions: toluene, $9.6 \mathrm{~cm}^{3}$; substrate, $15.9 \mathrm{mmol}$; catalyst, $0.1 \mathrm{~g}$; TPP/Rh, 6; temperature, $70^{\circ} \mathrm{C}$; time, $2 \mathrm{~h}$. 


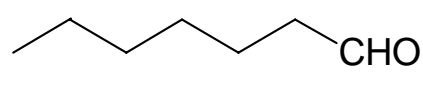

1
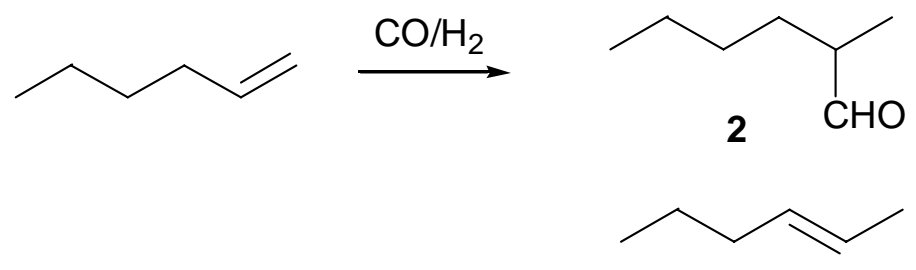

3

Scheme 1. Hydroformylation of 1-hexene 


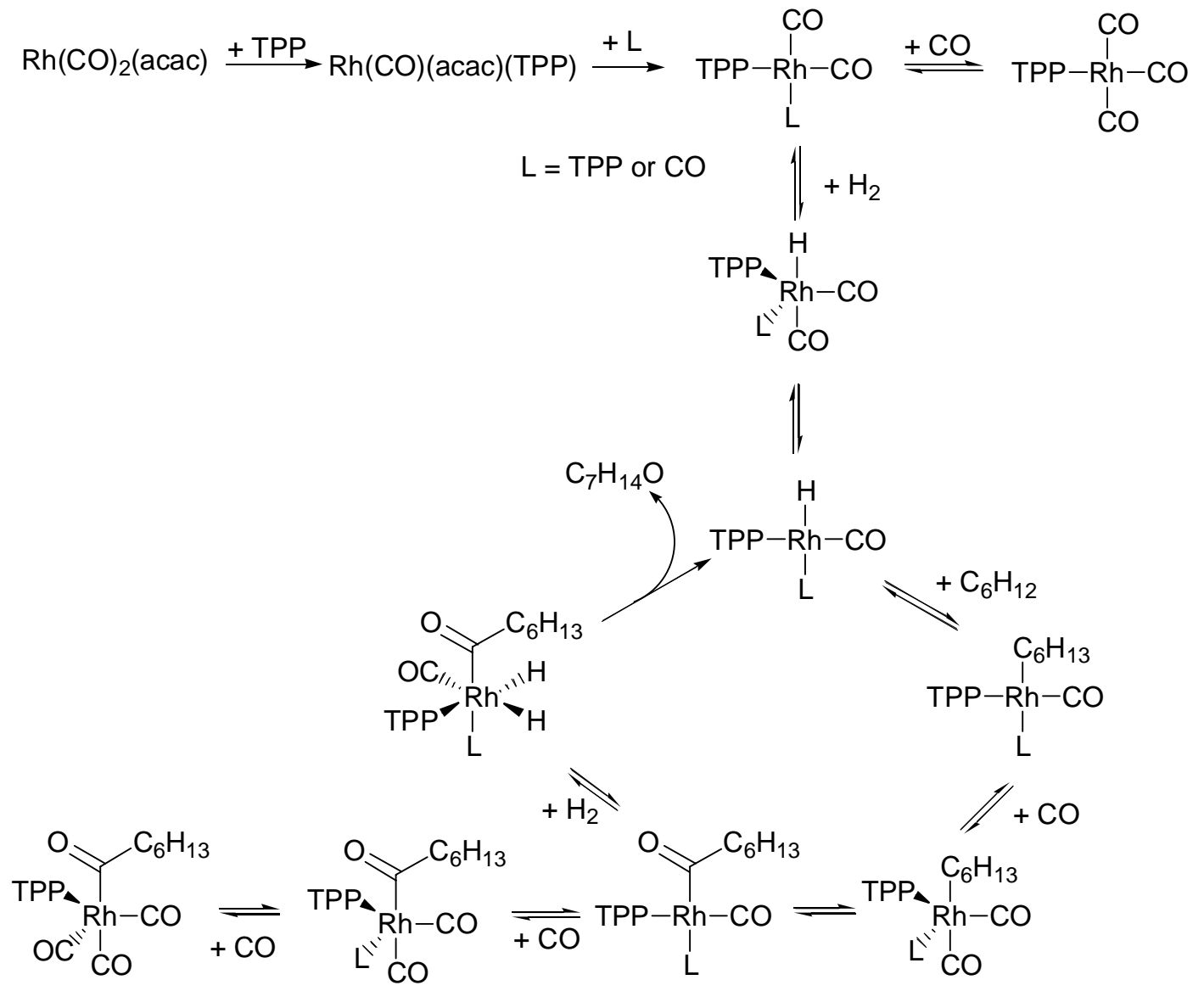

Scheme 2. Changes of rhodium complex structure during the catalyst preparation and the reaction. TPP = polystyrene bound triphenylphosphine 
(a)

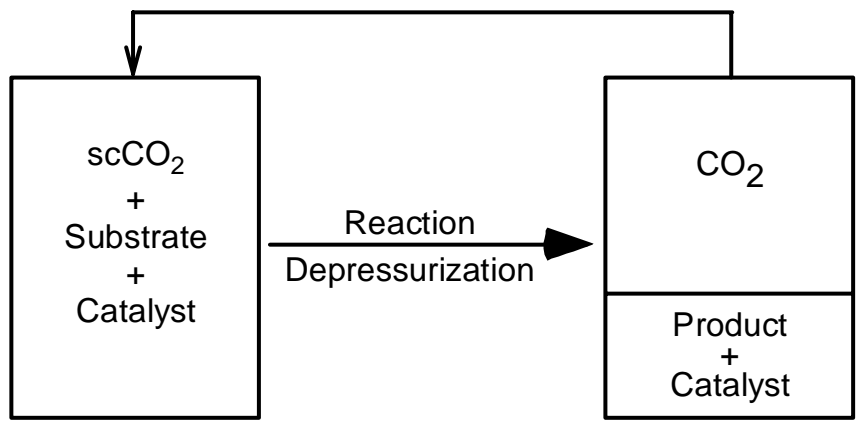

(b)

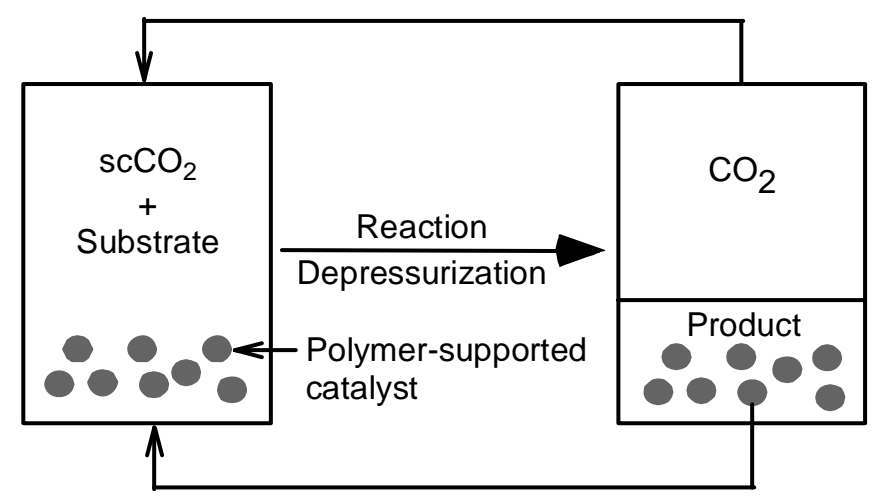

Fig. 1. Reaction systems in $\mathrm{scCO}_{2}$ using a homogeneous catalyst (a) and a polymer-supported catalyst (b). 


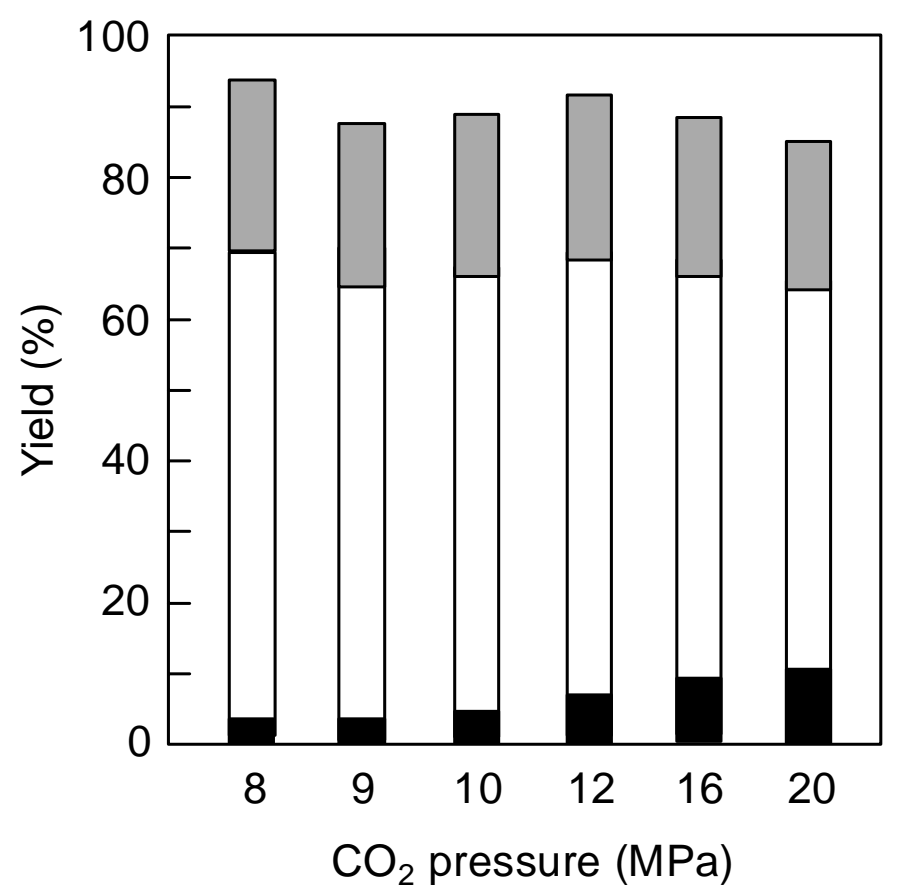

Fig. 2. Influence of $\mathrm{CO}_{2}$ pressure on hydroformylation of 1-hexene in $\mathrm{scCO}_{2}$ catalyzed by polymer-supported rhodium complex. ( $\square$ ), 1; ( $\square$ ), 2; ( $\square$ ), 3. Reaction conditions: substrate, 15.9 mmol; catalyst, $0.3 \mathrm{~g}(\mathrm{Rh}=138 \mu \mathrm{mol})$; TPP/Rh, 6; syngas, $4 \mathrm{MPa}$; temperature, $70^{\circ} \mathrm{C}$; time, $2 \mathrm{~h}$. 


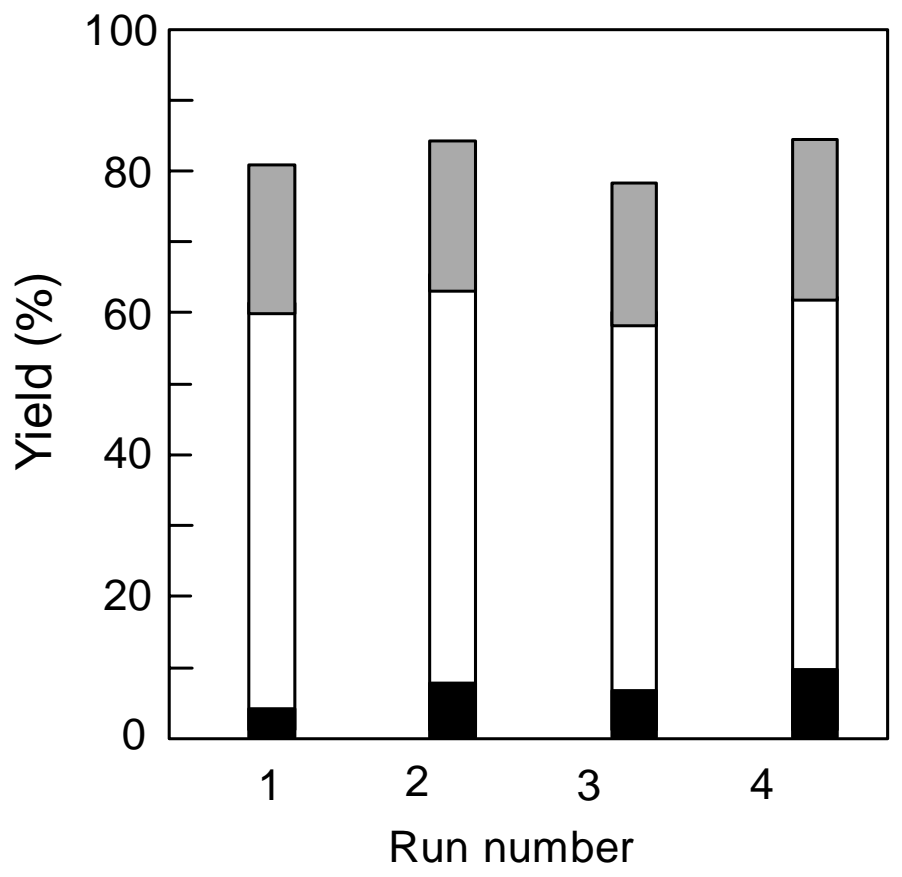

Fig. 3. Recycling of polymer-supported rhodium catalyst for hydroformylation of 1-hexene in $\mathrm{scCO}_{2}$.

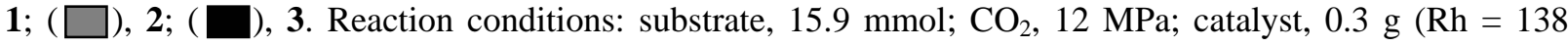
$\mu \mathrm{mol}$ ); TPP/Rh, 6; syngas, $4 \mathrm{MPa}$; temperature, $70^{\circ} \mathrm{C}$; time, $2 \mathrm{~h}$. 


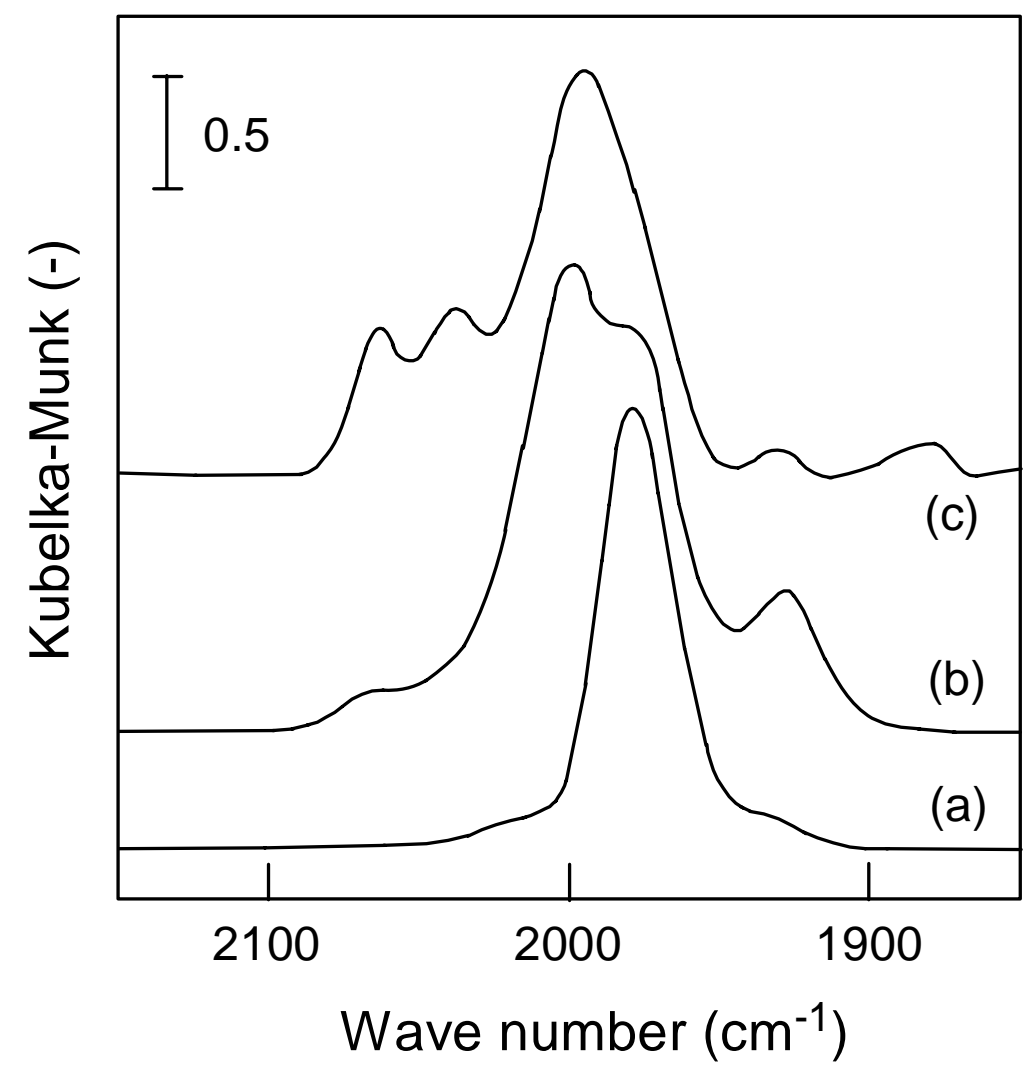

Fig. 4. Diffuse reflectance FT-IR spectra of polymer-supported rhodium catalyst measured (a) before and (b) after the syngas pretreatment and (c) after the hydroformylation in $\mathrm{scCO}_{2}$. TPP/Rh, 6; fixation time, $17 \mathrm{~h}$. The reaction conditions for the hydroformylation were the same with those for Fig. 3. 


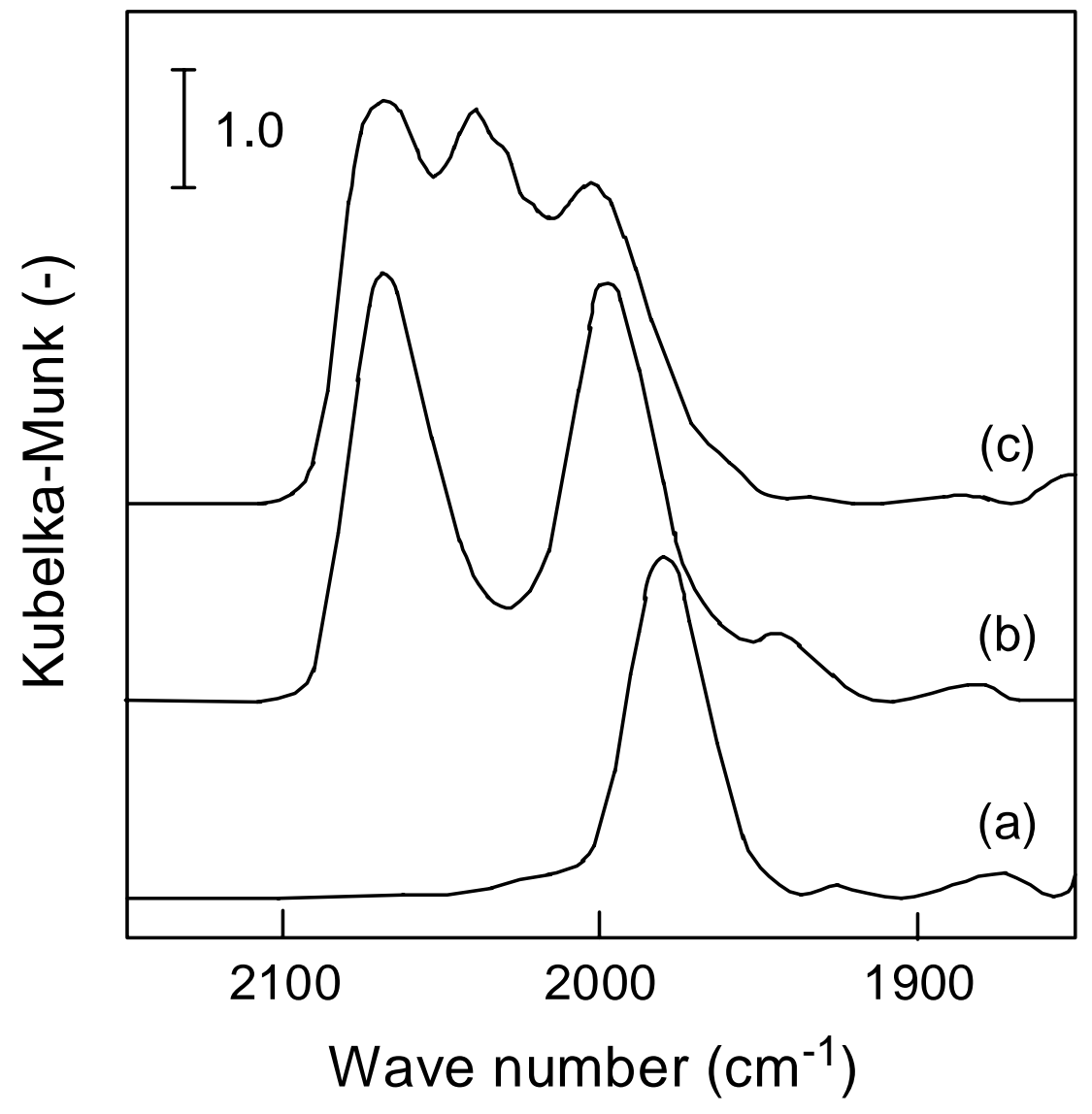

Fig. 5. Diffuse reflectance FT-IR spectra of polymer-supported rhodium catalyst with a TPP/Rh ratio of 2 measured (a) before and (b) after the syngas pretreatment and (c) after the hydroformylation in $\mathrm{scCO}_{2}$. Fixation time, $17 \mathrm{~h}$. The reaction conditions for the hydroformylation were the same with those for Fig. 3 except for the catalyst loading and the TPP/Rh ratio. 


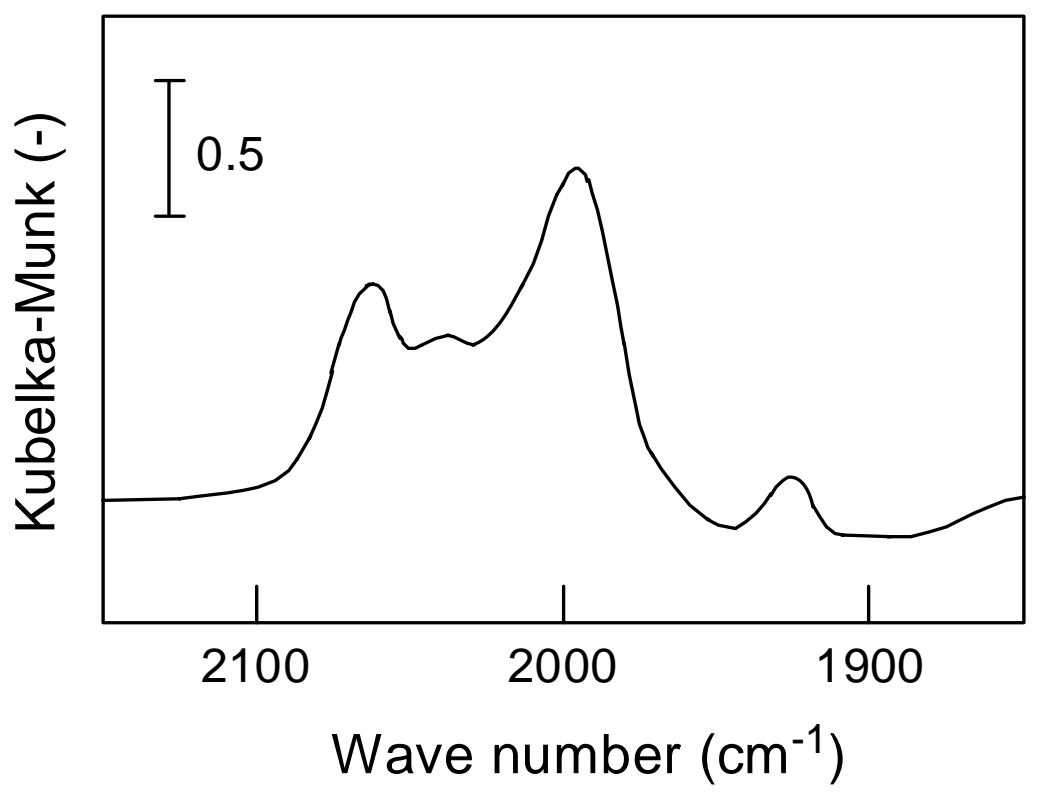

Fig. 6. A diffuse reflectance FT-IR spectrum of polymer-supported rhodium catalyst measured after the hydroformylation in toluene. TPP/Rh, 6; fixation time, $17 \mathrm{~h}$. The reaction conditions for the hydroformylation were the same with those for Table 3. 


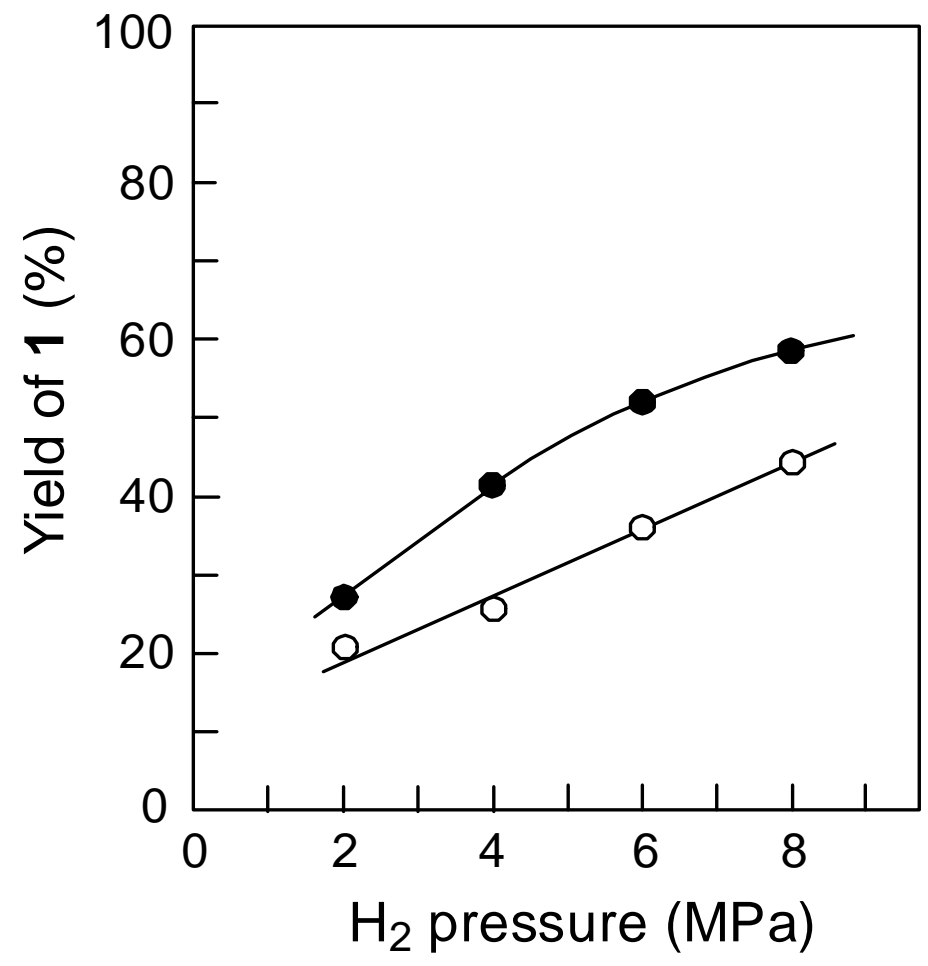

Fig. 7. Influence of $\mathrm{H}_{2}$ pressure on the yield of heptanal $\mathbf{1}(\mathrm{O})$ in $\mathrm{scCO}_{2}$ and $(\bigcirc)$ in toluene. Reaction conditions: substrate, $15.9 \mathrm{mmol}$; catalyst, $0.1 \mathrm{~g}(\mathrm{Rh}=46 \mu \mathrm{mol})$; TPP/Rh, 6; CO, $2 \mathrm{MPa}$; temperature, 70ㅇ; time, 2 h. Note that the catalyst amount is different from those for Fig. 1 and Table 3. 